\title{
A new fast-acting backup protection strategy for embedded MVDC links in future distribution networks
}

\author{
Lewis C. Hunter, Student Member, IEEE, Campbell D. Booth, Agusti Egea-Alvarez, Member, IEEE, \\ Adam Dyśko, Member, IEEE, Stephen J. Finney and Adrià Junyent-Ferré, Senior Member, IEEE.
}

\begin{abstract}
This paper presents a new fast-acting backup protection strategy for future hybrid ac-dc distribution networks. By examining the impedance measured by a distance protection relay measuring from the "ac-side" of the network, a unique characteristic is established for faults occurring on the "dc-side" of an embedded medium-voltage dc (MVDC) link, interconnecting two $33 \mathrm{kV}$ distribution network sections. Based on the identified impedance characteristic, appropriate settings are developed and deployed on a verified software model of a commercially available distance protection relay. To remain stable for ac-side faults, it is found that the tripping logic of the device must be altered to provide correct time grading between standard, ac, protection zones and the fast-acting dc region, which can identify faults on the dc system within $40 \mathrm{~ms}$. An additional confirmatory check is also employed to reduce the likelihood of mal-operation. Trials on a test system derived from an actual distribution network, which employs distance protection, are shown to provide stable operation for both ac-side and dc-side pole-pole and pole-pole-ground faults.
\end{abstract}

Index Terms - Distance protection, Medium-voltage directcurrent (MVDC), Power system protection, Smart grids.

\section{INTRODUCTION}

$\mathrm{D}$ ISTRIBUTION Network Operators (DNOs), as they evolve to become Distribution System Operators (DSOs) [1], are under increasing pressure to find new methods to accommodate growing levels of both embedded generation and new demand while using existing system assets as far as possible. Several regulator-funded projects in Great Britain (GB) have been tasked with investigating pioneering approaches to increase system flexibility within parts of their electrical distribution networks [2] [3].

Embedded medium-voltage direct current (MVDC) links provide DSOs with the capability to control network sections dynamically thus allowing substantial increases in power flows while remaining within the thermal ratings of transformers and conductors [4] [5]. This is being validated through demonstration projects notably in GB, where two DNOs have received regulator funding to deploy multi-megawatt $\mathrm{dc}$ demonstrators on their system [6] [7], and in Zhuhai, China [8]. Several vendors have recently began offering MVDC solutions for power distribution applications [9] [10]. Internationally,

Manuscript originally received $22^{\text {nd }}$ July 2019 ; revised $6^{\text {th }}$ December 2019 and $10^{\text {th }}$ March 2020; accepted $25^{\text {th }}$ April 2020.

This work has been supported through the Engineering and Physical Sciences Research Council (EPSRC) Centre for Doctoral Training in Future Power Networks and Smart Grids (EP/L015471/1)
MVDC technologies have been proposed for shipboard [11], rail traction [12], mining [13], rural low-power/long-distance electrification [14] and for generation collection network [15] [16] applications.

The protection required to safeguard controlled MVDC links from a dc-side fault needs to be fast acting otherwise the power electronic devices are likely to be irreversibly damaged [17] [18]. Generally, dc system protection requires faster fault clearance than ac systems [19].

The primary aim of this work is to determine whether conventional ac-side distance protection remains a valid and appropriate approach for the protection of hybrid ac-dc distribution networks. In particular, the studies conducted assess whether a suitably configured distance relay can provide sufficiently fast, backup protection for dc events should the converter station ac-side circuit breaker (CB) fail.

This paper examines the impedance, under faulted conditions, of an MVDC link as calculated by an ac-connected distance protection relay. No literature has been found which examines the ac-side impedance during a dc-side fault on power electronic links, however studies examining the impact of highvoltage dc (HVDC) and embedded generation (with ac fault ride through capability) are more readily available [20] [21].

The proposed backup protection scheme reported in this paper is assessed using a numerical distance protection relay model developed at the University of Strathclyde and corroborated by National Grid [22]. Studies conducted in the paper examine a section of actual distribution network in Scotland with protection settings derived from the local DNO's long term development statement.

Section II presents a brief overview of distance protection relaying and converter protection strategies. Section III introduces the study methodology and discusses system modelling parameters. Section IV examines the apparent impedance measured during a dc-side fault and implements the proposed fast-acting backup protection methodology. Discussion surrounding reported results is carried out in Section $\mathrm{V}$ followed by concluding remarks in Section VI.

In summary, this paper proposes a remote, fast-acting, backup protection strategy for dc-links embedded in distribution networks. The solution employs existing distance

L. C. Hunter, C. D. Booth, A. Egea-Alvarez and A. Dyśko are with the Department of Electronic and Electrical Engineering, University of Strathclyde, Glasgow, Scotland (e-mail: lewis.hunter.100@strath.ac.uk).

S. Finney is with the Department of Electronics and Electrical Engineering, The University of Edinburgh, Edinburgh, Scotland.

A. Junyent-Ferré is with the Department of Electrical and Electronic Engineering, Imperial College London, London, U.K. 
protection and measurement equipment and does not require communications.

\section{BACKGROUND}

This section reviews conventional relay setting guidance for distance protection of $33 \mathrm{kV}$ distribution networks. The protection strategy for a dc-side fault on an MVDC link is outlined.

\section{A. Distance Protection Operation}

The decision to trip or not (and whether the trip is instantaneous or occurs after a time delay) within distance protection relays is proportional to the impedance between the measurement point and the fault location [23]. This principle allows operational zones, typically three (Z1, Z2, and Z3), to be defined as presented in Fig. 1 [24]. Zone 1 generally reaches to approximately $80 \%$ of the first protected feeder (Line RS in Fig. 1) to prevent overreach into Zone 2 which would be caused by errors in the transducers, relay and estimation of line parameters. Zone 2 is typically set to $120 \%$ impedance of the protected line (120\% of Line RS). Zone 3 generally reaches to $120 \%$ of the combined impedance of lines RS and ST [25]. Maximum distance protection clearance times adopted by a particular DNO are presented in Table I [26]. The delayed trip times for $\mathrm{Z} 2$ and $\mathrm{Z} 3$ are designed to ensure that in the event of failure of the main protection to operate (i.e. Z1) then other distance relays will break in the vicinity.

Distance protection is used commonly in transmission and primary distribution systems to provide both fast acting main protection in addition to backup functionality [25].

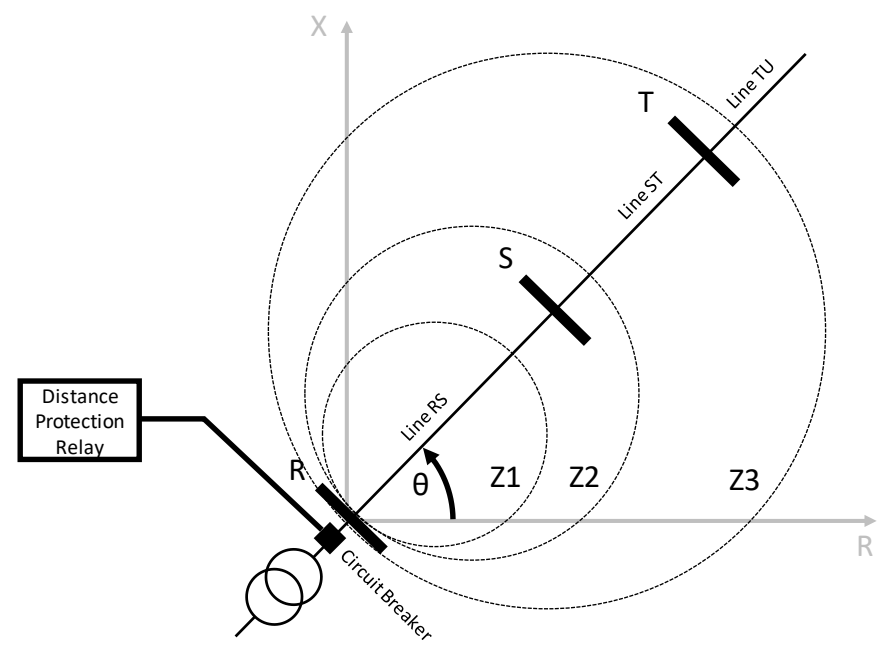

Fig. 1. Distance protection zone diagram with Mho characteristic

TABLE I

MAXimum ClearanCe TIMES FOR DisTANCE PROTECTION SCHEMES AS SPECIFIED BY A SCOTTISH DNO

\begin{tabular}{cc}
\hline \hline Zone & $\begin{array}{c}\text { Maximum permissible } \\
\text { clearance time }(\mathrm{s})\end{array}$ \\
\hline $\mathrm{Z} 1$ & 0.150 \\
$\mathrm{Z} 2$ & 0.500 \\
$\mathrm{Z} 3$ & 1.300 \\
\hline \hline
\end{tabular}

\section{B. Converter Protection Strategy for DC Faults}

While grid-connected converters can provide limited and controlled fault current contribution to ac-side faults, via the converter's IGBTs (insulated-gate bipolar transistor) [27], their performance during a dc fault is effectively uncontrolled [17] for most converter topologies and can only be overcome at the expense of significant power losses [28]. When a dc-side fault occurs on a dc link and is detected by the converter controller, the first step taken by the protection system is to block commutation of the switching devices. This prevents the power electronic devices being subjected to high fault currents which would only be limited by system and converter filter impedances [17]. The dc-side capacitors discharge forcing the freewheel diodes, placed across the power switches, into conduction as shown in Fig. 2 for a two-level topology. The converter essentially becomes an uncontrolled rectifier with current only being limited by the ac-side inductance between the source and the converter [29]. Bypass devices (not shown in Fig. 2), often high capacity thyristors, may be installed to divert current away from the diodes allowing time for protection to operate [30] [31].

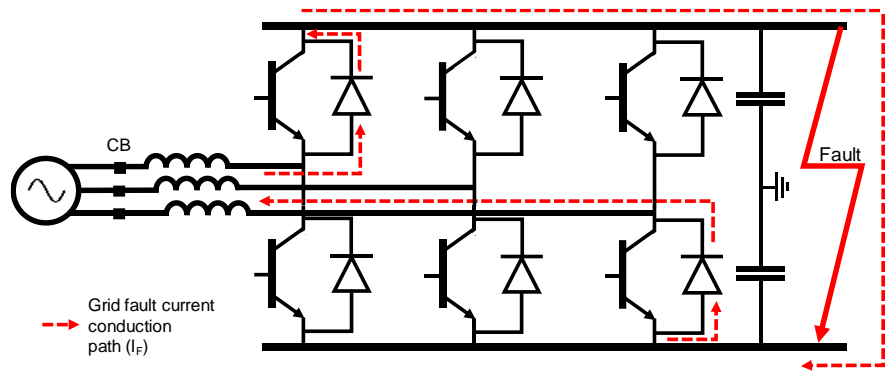

Fig. 2. Example of converter fault path through freewheel diode for a pole to pole (PP) fault

The ac-side $\mathrm{CB}$ of the converter should open to isolate current infeed to the link. This needs to happen quickly to protect the parallel diodes from overheating and failing critically [32].

Should any of these steps fail (converter controller failure, trip signal failure, maloperation of ac-side $\mathrm{CB}$ ), the converter could be left in a damaging (e.g. freewheeling diodes are typically not rated for continuous operation) uncontrolled rectifying state as described previously.

\section{Study Methodology}

This section will present the modelling methodology for the study. A two-stage simulation process will be employed. Sampled voltages and currents are generated via detailed transient simulation. These waveforms are then used as inputs to a software-based distance protection relay simulator.

\section{A. Network Modelling}

The network section modelled is based upon an area of the $33 \mathrm{kV}$ network in the south of Scotland where the benefits of introducing embedded MVDC links has been shown via simulation [33]. 


\section{B. Converter Modelling}

The converter has a power rating of 35 MVA operating under a two-level symmetrical monopole configuration with dc voltage $\left(V_{d c}\right)$ of $\pm 27 \mathrm{kV}$, which is broadly equivalent to $33 \mathrm{kV}$ rms line-line voltage from an insulation perspective.

The per-unit impedance of the converter filter is $10 \%$ with a wye-delta transformer of $20 \%$ impedance (referred to the converter base impedance) connected to the ac network to limit fault current during dc-side faults and improve power quality during normal operation.

Fig. 3 presents a control overview diagram of the MVDC link. The converter control deploys a standard inner current control strategy [34]. Station A is set to maintain a $P-Q$ reference while Station B deploys a $V_{d c}-Q$ control under normal pre-fault operation [35]. Note that the pre-fault operating control strategy does not affect the proposed protection solution introduced later in the paper and is only used to create a prefault power transfer across the dc link.

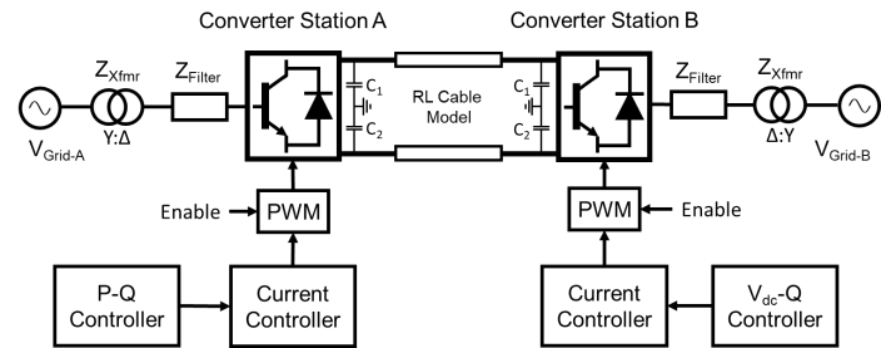

Fig. 3. MVDC link control topology

When a fault is detected, the converter would behave as outlined in Section II.B. In summary, switching of the IGBTs would be blocked and the bypass thyristors enabled. The bypass thyristors are activated when the absolute value of an instantaneous current entering the converter is equal to or greater than the user-definable current threshold $\left(I_{\max }\right)$. (In this model $I_{\max }$ is set as 1.1 times the rated current of the converter). Should an overcurrent be detected on any phase, the bypass thyristors will be enabled to create a parallel conduction path across the IGBT diodes. The freewheeling diodes and bypass thyristors conduct fault current until the converter is isolated via ac-side breakers. Fig. 4 presents an overview of the bypass controller.

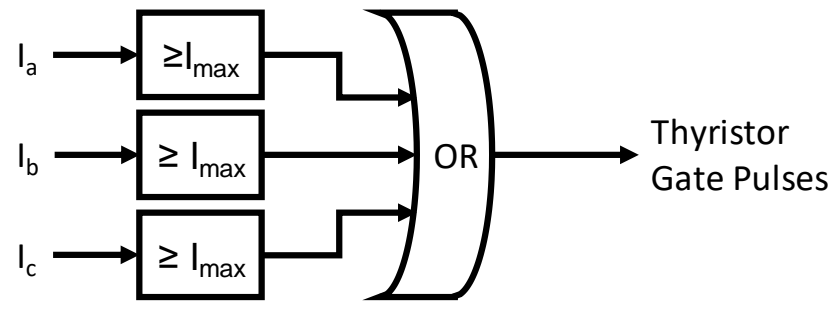

Fig. 4. Overview of bypass thyristor controller

\section{Distance Relay Modelling}

The Dynamic Protection Modelling Controller (DPMC) [22] software package is used to determine the impedance of the network measured during steady state and fault conditions. This software was developed to assist the local Transmission System Operator (TSO), National Grid, in the post-fault investigation of power system performance under various transient faults and events. The relay models within DPMC are based upon and validated against commercially available devices.

The software uses sampled three phase voltages and current values along with a relay setting file as inputs. Tripping times of the relay are calculated according to the setting file logic. An $\mathrm{R}-\mathrm{X}$ locus diagram is also generated for visual interrogation of how the apparent impedance changes as the event progresses.

\section{Simulation Strategy}

Fig. 5 summarizes the developed simulation approach.

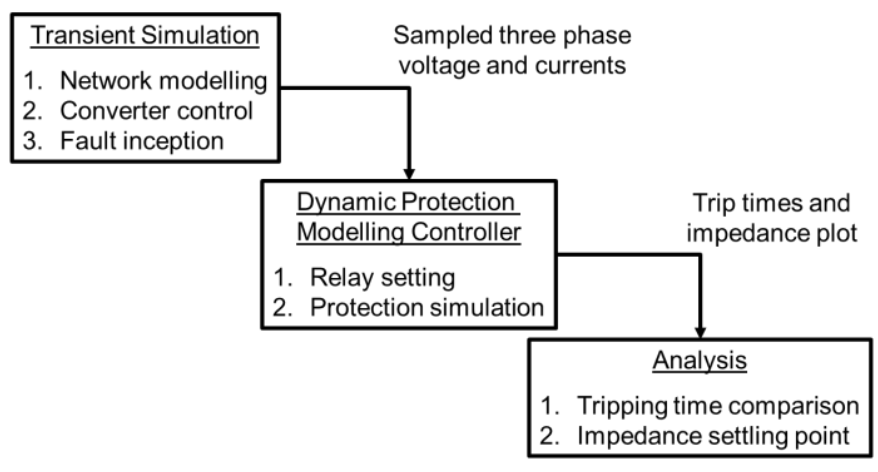

Fig. 5. Simulation flow diagram

\section{CAse Studies}

Two main studies are presented in this paper. The first determines how a dc-side fault would be observed by ac-side distance protection devices. The second establishes if the relay can be configured to react to such a fault in an appropriate manner without compromising operation of the existing ac system protection zones.

\section{A. Test Network}

The test network used for modelling is presented in Fig. 6 where the characteristic impedance of all lines is $(0.17+\mathrm{j} 0.3) \Omega / \mathrm{km}$. AC conductors are modelled as lumped element R-L components while the dc cable is implemented as a single $\pi$-section with the shunt capacitance modelled via the dc capacitors [36]. The network is a three-bus system where a $10 \mathrm{~km} 35 \mathrm{MW}$ MVDC link has been introduced at busbar B. Key network and converter parameters used in the model are summarized in the appendix.

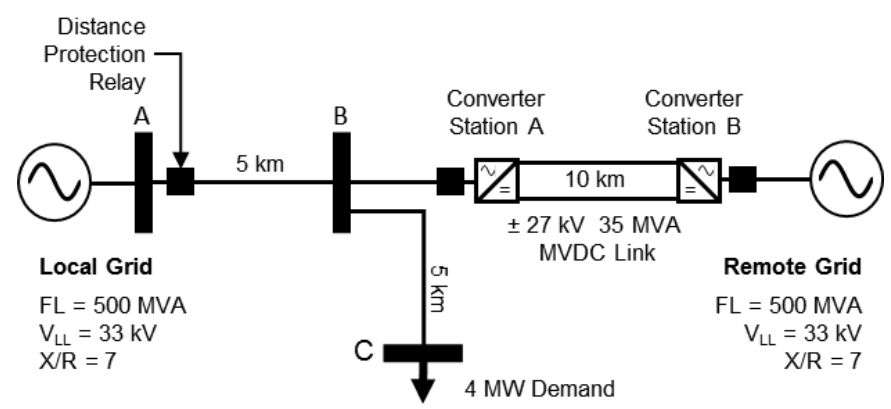

Fig. 6. Test network section

\section{B. Relay Setting Parameters}

Relay settings are assigned in accordance with [37] [38] with trip times selected to ensure that fault clearance occurs inside of the maximum permissible clearance times outlined in Table 
I. The angle $(\theta)$ of the mho characteristic is established using the line impedance $(0.17+\mathrm{j} 0.3 \Omega / \mathrm{km})$ and by considering the ratio between the downstream line reactance and resistance as specified by equation (1) where $X_{\text {line }}$ is the reactance of the protected line and $R_{\text {line }}$ is the resistance. The apparent impedance of the conductor $\left(Z_{\text {line }}\right)$ is calculated in equation (2). Equations (3) - (5) calculate the standard ac protection zone settings.

$$
\begin{gathered}
\theta=\tan ^{-1}\left(\frac{X_{\text {line }}}{R_{\text {line }}}\right)=\tan ^{-1}\left(\frac{0.3}{0.17}\right)=60.5^{\circ} \\
Z_{\text {line }}=\sqrt{\left(R_{\text {line }}^{2}+X_{\text {line }}^{2}\right)}=\sqrt{0.17^{2}+0.3^{2}} \\
=0.345 \Omega / \mathrm{km}
\end{gathered}
$$

Key distance zone setting parameters are outlined in Table II (note that the impedances are primary referred and do not take current transformers (CT) or voltage transformers (VT) ratios into account).

TABLE II

SUMMARY OF RELAY SETTING PARAMETERS

\begin{tabular}{ll}
\hline \hline \multicolumn{1}{c}{ Parameter } & Value \\
\hline Mho angle $\left({ }^{\circ}\right)$ & 60.5 \\
Z1 $(\Omega)$ & 1.4 \\
Z2 $(\Omega)$ & 2.1 \\
Z3 $(\Omega)$ & 6.2 \\
Z2 fault delay [phase \& earth] (s) & 0.3 \\
Z3 fault delay [phase \& earth] (s) & 1.1 \\
\hline \hline
\end{tabular}

\section{Fault Analysis}

It is assumed that the MVDC converter does not provide any fault current contribution for ac-side faults (i.e. switching of IGBTs is paused), although it is recognized that significant fault infeed from a converter could influence relays' impedance measurements for ac faults [39].

The behavior and performance of the distance protection relay will now be outlined, initially for ac-side faults and then for pole-to-pole-to-ground (PPG) dc-side faults.

\section{1) AC-side zone verification}

To verify the correct setting of the distance protection relay for standard ac system faults (i.e. Z1, Z2 and Z3), six fault studies were conducted, covering a wide range of fault locations and types. Transient simulations were carried out using a model implemented in Matlab's Simulink (SimPowerSystems). Faults are simulated at $0.5 \mathrm{~s}$ in all cases.

Table III (where G indicates the detection of a fault to ground and $\mathrm{P}$ signifies a phase fault) presents which of the internal comparators of the distance protection relay leads to the tripping of the $\mathrm{CB}$ for each fault study. For the scenarios conducted the relay operates within the required tripping times defined previously in Table I.
TABLE III

SiMPLIFIED RELAY LOG FOR Z1, Z2, Z3 AC-SidE TEST FAULTS

\begin{tabular}{c|c|c|c|c|c|c|c|c}
\hline \multicolumn{2}{c}{ Scenario } & \multicolumn{2}{c|}{$\begin{array}{c}\text { Time } \\
\text { of }\end{array}$} & \multicolumn{3}{|c}{ Tripping Element } \\
Fault Location & $\begin{array}{c}\text { Fault } \\
\text { Type }\end{array}$ & $\begin{array}{c}\text { Trip } \\
\text { (s) }\end{array}$ & G & P & G & P & G & P \\
\hline Line AB midpoint (Z1) & A-B-C-G & 0.5144 & & & & & & \\
\hline Busbar B (Z2) & A-B-C-G & 0.8229 & & & & & & \\
\hline Busbar C (Z3) & A-B-C-G & 1.6221 & & & & & & \\
\hline Line AB midpoint (Z1) & A-G & 0.5178 & & & & & & \\
\hline Busbar B (Z2) & B-C & 0.8183 & & & & $\bullet$ & & \\
\hline Busbar C (Z3) & C-A-G & 1.6254 & & & & & & \\
\hline \hline
\end{tabular}

2) DC-side faults

For dc-side faults, it is assumed that the converter's ac-side CB at Station A (ac-side) fails to operate for the event. Both Station A and Station B block commutation upon the instigation of the fault with the remote converter station (Converter Station B) disconnecting from the ac network within four ac cycles $(80 \mathrm{~ms})$. Fault inception is at $0.5 \mathrm{~s}$ and occurs at the midpoint of the dc link.
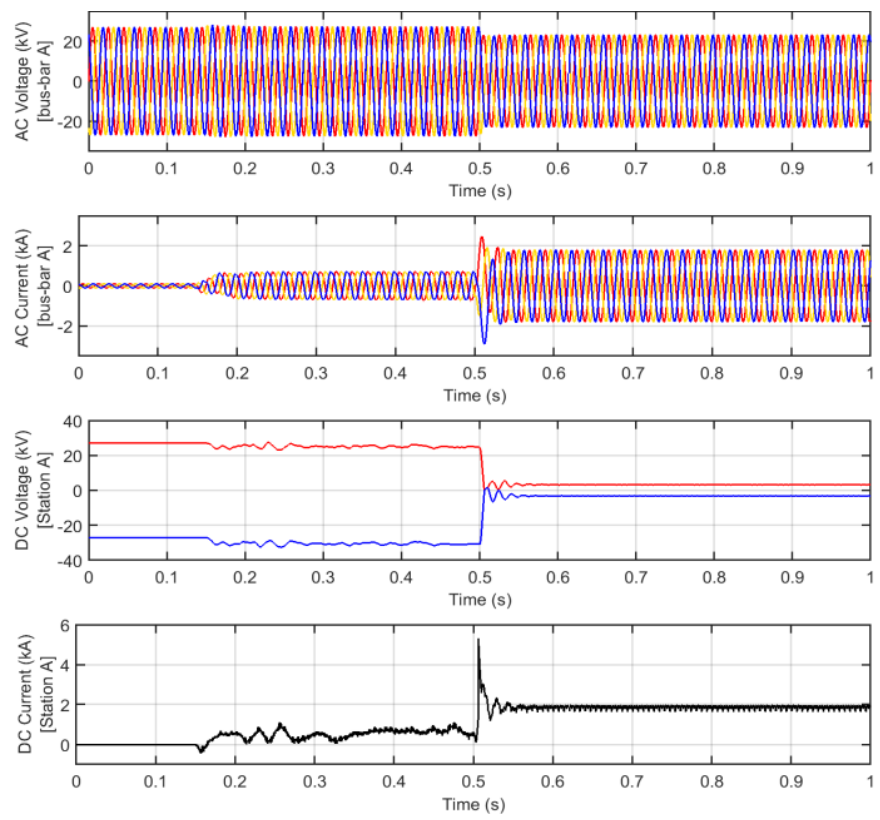

Fig. 7. Voltage and currents for ac and dc systems during pole-pole-ground fault at the midpoint of the dc link

Fig. 7 presents the ac-side voltage and current as measured at the distance relay in addition to the dc-side voltage and current measured at Station A. In the simulation, converter initialization occurs up to $0.15 \mathrm{~s}$, then a pre-fault transfer of $30 \mathrm{MW}$ from converter A to B is established.

The impedance locus diagrams in Fig. 8 represents the timevarying apparent impedances calculated by the distance protection relay during the event. Each subplot shows a different calculation of the impedance based on phase to phase and phase to ground measurements (i.e. A-G, B-G, C-G, A-B, B-C, C-A). These subplots also show the standard distance protection zones (i.e. Z1 - Z3). The "trails" (shown in green in Fig. 8) represent the "history" of the calculated impedance over time starting from the time of fault inception - for example for AG, one can see that the measured impedance has "entered" from the right and transited (via an approximately circular loci) to its "steady state" - this evolution of measured impedance is 
due to the initial fault, any arcing, and the measurement algorithm (e.g. discrete Fourier transform etc.) within the relay stabilising during and after the initial transient/discontinuity in the measured voltages and currents.

The impedance loci during the fault reside significantly outside the standard ac protection zones of the distance protection relay. The loci do however evolve towards a sustained value of approximately $(2.5+\mathrm{j} 10.8) \Omega$ in the case of a PPG fault at the midpoint of the dc link.
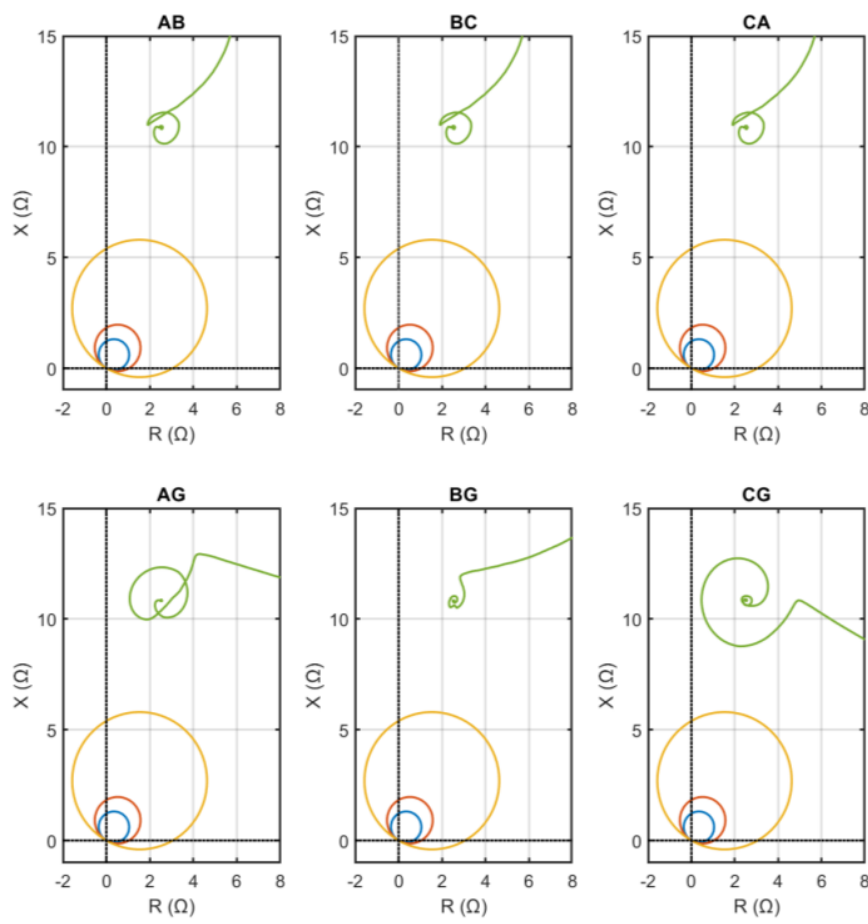

Fig. 8. R-X diagram for a PPG fault at the mid-point of the dc link

\section{3) Proposed Protection Scheme}

The highly inductive nature of the fault outlined in Fig. 8 creates a degree of confidence as to where the impedance loci of a dc-side PPG event settles. This settling point resides significantly outside of the resistive, load-serving, operational area of conventional distribution networks. The inductive nature of the fault is associated with significant inductance (i.e. converter filters and transformer) placed between the distance protection relay and the converter (for purposes outlined previously). This highly inductive characteristic could allow a distance protection relay to detect dc-side PPG/PP faults and trip quickly, using appropriate logic, should primary protection fail.

Conventional overcurrent protection is unlikely to provide reliable and fast backup disconnection as the current infeed to the fault is expected to be very low (again due to the significant inductance in the system). In the case of the simulated waveform for a PPG fault (Fig. 7), the fault current is only approximately 2.5 to 3 times greater than the load current.

Many modern digital distance protection relays include customizable zones whose characteristics can be manipulated as per network requirements. It is hypothesized that a fast-trip quadrilateral characteristic, shown as zone 4 (Z4) in Fig. 9, could potentially provide sufficiently quick backup protection to an embedded MVDC link for dc-side PPG and PP faults.

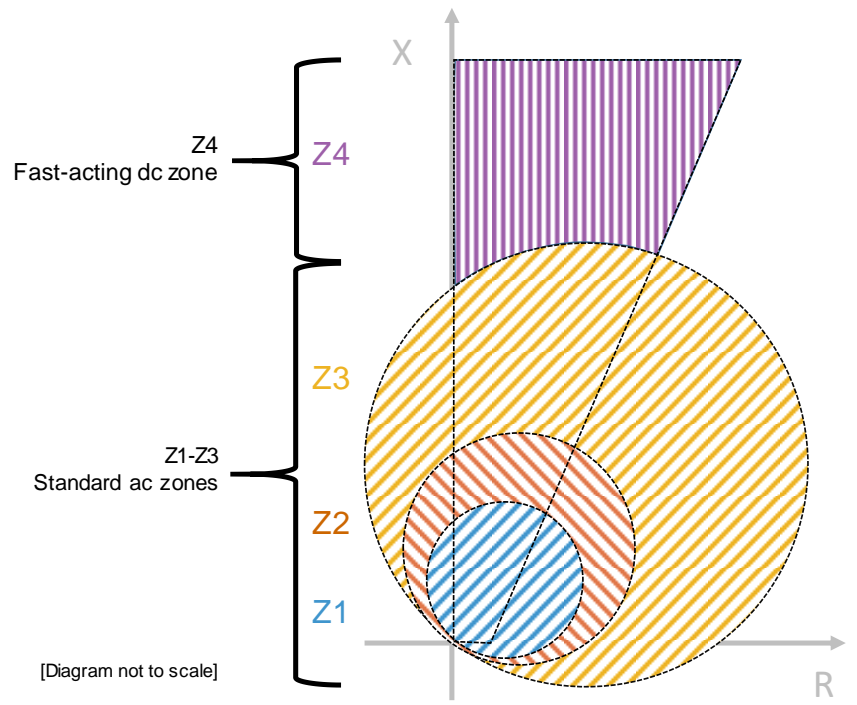

Fig. 9. R-X diagram showing conventional Z1-Z3 tripping zones and fast-acting Z4 quadrilateral area for detection of dc-side faults.

For a dc-side fault, it is important that the relay only trips for the area outside of the $\mathrm{Z3}$ Mho characteristic but within the bounds of the Z4 quadrilateral (the area shaded with purple vertical lines - Fig. 9). Under conventional relay setting this would not be an issue as the time grading (i.e. tripping delay) increases with increasing zone number. However, with the solution proposed a fault detected in $\mathrm{Z} 4$ should react much quicker than both $\mathrm{Z} 2$ and $\mathrm{Z3}$. A fault which resides in either Z2 or Z3 but also within the quadrilateral Z4 characteristic should trip with the time delays associated with $\mathrm{Z} 2$ and $\mathrm{Z} 3$ to ensure correct discrimination. The logic tripping expression for the fast-acting $\mathrm{Z} 4$ area $\left(\mathrm{Z} 4_{\text {TRIP }}\right)$ is therefore presented in equation (6). Note that since $Z 2$ is a subset of $Z 3$, a Z2 condition is not required in the tripping logic.

$$
Z 4_{T R I P}=\overline{Z 3} \cdot Z 4
$$

From the R-X plots outlined previously (Fig. 8), it is established that dc-side faults appear as symmetrical events to the distance relay for PPG faults. With the majority of ac faults on the distribution system being non-symmetrical events [40], it is proposed that all six $\mathrm{Z} 4$ comparators (i.e. $\mathrm{AB}, \mathrm{BC}, \mathrm{CA}, \mathrm{AG}$, $\mathrm{BG}, \mathrm{CG})$ must be active to permit the fast dc trip zone. The introduction of this additional check increases the certainty of a dc-side fault being detected rather than a remote ac fault. Confidence in such a backup scheme is vital due to the wider geographical area and larger number of customers liable to be disconnected should the $\mathrm{Z} 4$ scheme trip.

\section{Proposed Relay Setting Parameters}

The maximum (primary referred) resistance and reactance of the system, as measured by the distance protection relay, for a fault on the dc link is calculated via equations (7) and (8). A $20 \%$ grading margin is added to the apparent impedance to calculate the reach of $\mathrm{Z} 4\left(\mathrm{ZA_{ \text {Reach } }}\right)$ as in equation (9). This uncertainty allows for errors in line length and transducers but 
also considers the nonlinearities associated with the ac to dc conversion system.

$$
\begin{gathered}
R_{Z 4}=\sum\left[R_{L_{a c}}, R_{X f m r}, R_{F}, R_{L_{d c}}\right] \\
X_{Z 4}=\sum\left[X_{L_{a c}}, X_{X f m r}, X_{F}\right] \\
Z 4_{\text {reach }}=1.2 \times \sqrt{R_{Z 4}^{2}+X_{Z 4}^{2}}
\end{gathered}
$$

$R_{Z 4}$ and $X_{Z 4}$ are the maximum expected resistance and reactance associated with a dc-side fault. $R_{L_{a c}}$ and $X_{L_{a c}}$ represent the resistance and reactance of the ac conductors between the distance relay and the converter's ac-side CB. $R_{L_{d c}}$ is the resistance of the dc conductors between converter Station A and Station B. $R_{F}$ and $X_{F}$ are the resistance and reactance of the ac filters at Station A. Finally, $R_{X f m r}$ and $X_{X f m r}$ are the resistance and reactance of the converter transformer. Note that the reactance of the dc line is not included in the calculation of $X_{Z 4}$ as there should be no ac component within a dc system.

The quadrilateral line setting angle for the proposed solution employs equation (1) but using the resistance and reactance values determined by equations (7) and (8). The angle of the Z4 reach can be computed as per equation (10).

$$
\theta=\tan ^{-1}\left(\frac{X_{Z 4}}{R_{Z 4}}\right)
$$

For the network presented previously in Fig. 6, setting parameters are calculated as follows. Note that the transformer winding resistance has been assumed to be negligible for these case studies.

$$
\begin{gathered}
R_{Z 4}=[(0.17 \times 5)+0.3+(0.17 \times 10)]=2.9 \Omega \\
X_{Z 4}=[(0.3 \times 5)+6.28+3.14]=10.9 \Omega \\
Z 4_{\text {reach }}=1.2 \times \sqrt{2.9^{2}+10.9^{2}}=13.5 \Omega \\
\theta=\tan ^{-1}\left(\frac{10.9}{2.9}\right)=75.1^{\circ}
\end{gathered}
$$

A summary of all the proposed relay setting parameters is outlined in Table IV. A tripping delay of $100 \mathrm{~ms}$ is proposed for $\mathrm{Z} 4$ to provide time for the converter's main protection scheme to detect and block (assumed maximum $20 \mathrm{~ms}$ ) and isolate the fault through opening the ac-side breaker (assumed maximum $60 \mathrm{~ms}$ ), with a discrimination margin of $20 \mathrm{~ms}$ (in effect, clearance would be after a further $80 \mathrm{~ms}$ or so due to circuit breaker action).
TABLE IV

\begin{tabular}{ll}
\multicolumn{1}{c}{ PUMMARY } & \multicolumn{1}{c}{ Palue } \\
\hline \hline Mho line angle $\left({ }^{\circ}\right)$ & 60.5 \\
Quadrilateral line angle $\left(^{\circ}\right)$ & 75.1 \\
Z1 reach $(\Omega)$ & 1.4 \\
Z2 reach $(\Omega)$ & 2.1 \\
Z3 reach $(\Omega)$ & 6.2 \\
Z4 reach $(\Omega)$ & 13.5 \\
Z4 resistive reach $(\Omega)$ & 2.9 \\
Z2 delay $(\mathrm{s})$ & 0.300 \\
Z3 delay $(\mathrm{s})$ & 1.100 \\
Z4 delay $(\mathrm{s})$ & 0.100 \\
\hline \hline
\end{tabular}

\section{E. DC Fault Simulation Studies}

To validate the proposed relay setting configuration, a series of simulated PPG and PP events were applied at three locations on the dc line: at the terminals of converter A $(0 \mathrm{~km})$, the middle of the dc line $(5 \mathrm{~km})$ and at the terminals of converter B

\begin{tabular}{|c|c|c|c|c|c|c|}
\hline \multicolumn{2}{|c|}{ Scenario } & \multirow{2}{*}{ Time of Trip (s) } & \multicolumn{4}{|c|}{ Tripping Zone } \\
\hline Location & Fault Type & & $\mathbf{Z 1}$ & $\mathbf{Z 2}$ & $\mathbf{Z 3}$ & $\mathbf{Z 4}$ \\
\hline $0 \mathrm{~km}$ & PPG & 0.634 & & & & 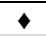 \\
\hline $5 \mathrm{~km}$ & PPG & 0.637 & & & & $\bullet$ \\
\hline $10 \mathrm{~km}$ & PPG & 0.639 & & & & $\bullet$ \\
\hline $0 \mathrm{~km}$ & PP & 0.635 & & & & $\bullet$ \\
\hline $5 \mathrm{~km}$ & PP & 0.637 & & & & $\bullet$ \\
\hline $10 \mathrm{~km}$ & $\mathrm{PP}$ & 0.638 & & & & $\bullet$ \\
\hline
\end{tabular}
$(10 \mathrm{~km})$. Faults are applied at $0.5 \mathrm{~s}$ with a fault resistance of $0.1 \Omega$. The tripping times and associated detection zones for these dc-side faults are presented in Table V. Fig. 10 presents the associated R-X locus diagrams for a PPG fault at the midpoint of the dc link.

TABLE V

RELAY LOG DC-SIDE FAULTS
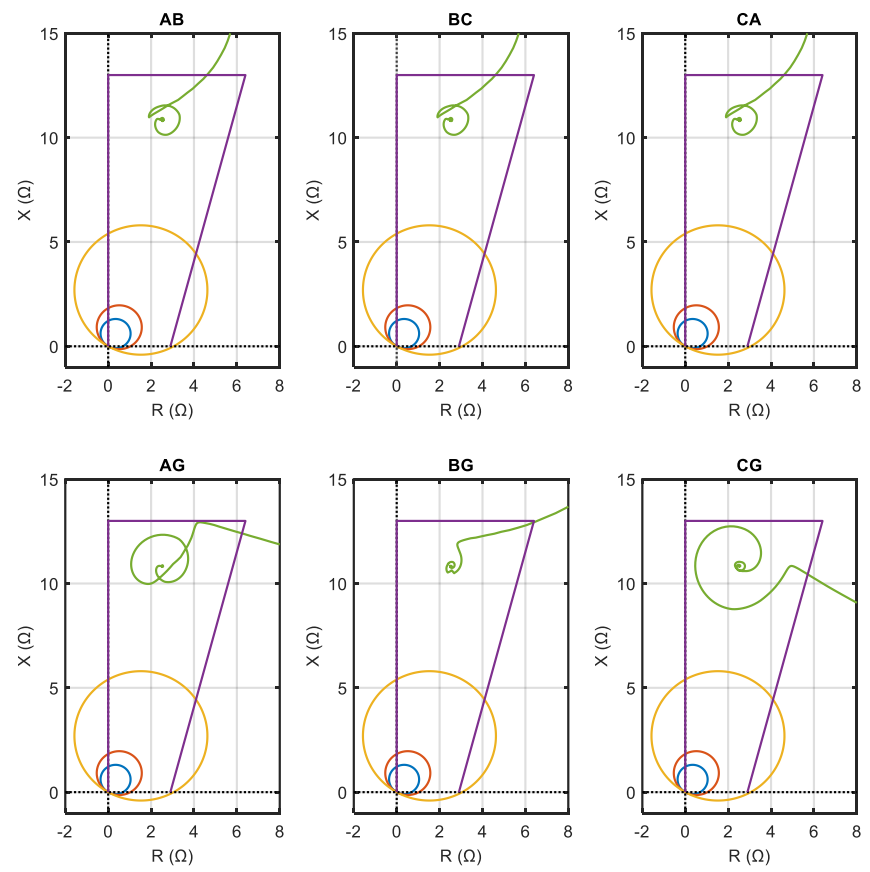

$-\mathrm{Z} 1-\mathrm{Z2}-\mathrm{Z3}-\mathrm{Z4}-$ Apparent Impedance

Fig. 10. R-X diagram for a PPG fault at dc link midpoint (5 km)

It is observed from Table $\mathrm{V}$ that the relay correctly identifies all PPG and PP faults with a maximum tripping time of $0.639 \mathrm{~s}$, $0.139 \mathrm{~s}$ after fault inception in the case of the PPG fault at $10 \mathrm{~km}$. This time incorporates the (user-configurable) $100 \mathrm{~ms}$ 
Z4 delay outlined previously to allow for grading with the embedded MVDC link's main converter protection scheme. Effectively, the relay detects the presence of the fault residing inside $\mathrm{Z} 4$ in $40 \mathrm{~ms}$. The tripping time could potentially be shorter if desired, through specifying a shorter delay time.

The final impedance settling points are presented in Fig. 11 for PPG faults and in Fig. 12 for PP events. It is shown that the relay is sensitive to all PPG and PP faults along the MVDC link. These plots confirm that the measured ac-side impedance only increases horizontally along the resistive axis proportionally to the increasing distance between the measurement point and fault location for dc-side PPG and PP faults. Accordingly, for any resistive fault, the locus of the apparent impedance would be shifted to the right with the magnitude of shift being proportional to the fault resistance. There is no possibility of a resistive fault on the link encroaching on other zones, so to detect faults with significant fault resistance would simply require an extension of the $\mathrm{Z} 4$ boundaries.

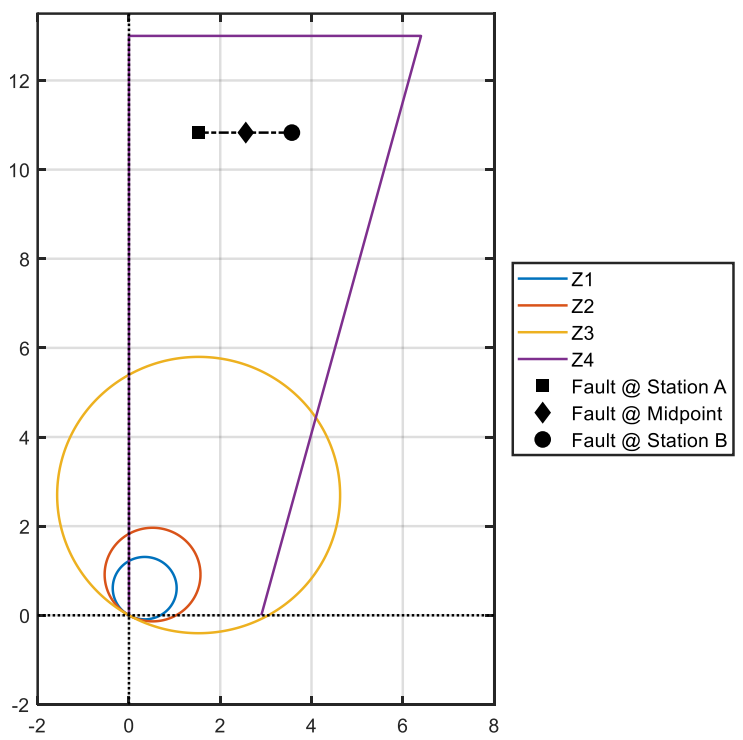

Fig. 11. Final apparent fault impedance settling points for PPG events at Station A, mid-point and Station B

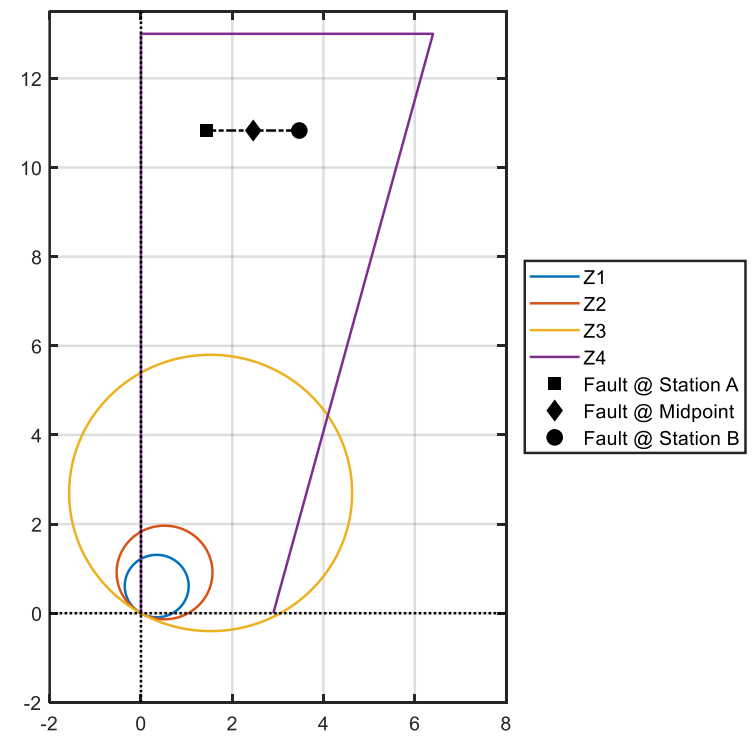

Fig. 12. Final apparent fault impedance settling points for PP events at Station A, mid-point and Station B

\section{DISCUSSION}

Fast-acting distance protection offers an innovative method of backing up main converter protection for dc-side PPG and PP faults under a symmetrical monopole operating topology. Remote backup protection of an MVDC link is likely to give system operators higher confidence in deploying and protecting dc solutions within their networks. Fast backup protection may allow simpler and cheaper converter topologies to be deployed on distribution networks with the DSO remaining confident that assets are secured by both main protection at converter stations and through remote network protection schemes.

The back-up protection reported here would not be capable of detecting single pole to ground (PG) faults for a symmetrical monopole. When a PG fault occurs, the link effectively becomes a monopole with a metallic/earth return. The transfer current remains constant, as the system is still controlled, while the dc voltage tends towards twice the nominal pole to ground voltage (i.e. $54 \mathrm{kV}$ in the case of a $\pm 27 \mathrm{kV}$ system) [41]. From the ac-side, there is no change in the ac voltage or currents and therefore the distance relay would not be sensitive to such faults.

Depending upon network topology, it may be undesirable to permanently trip the $\mathrm{CB}$ at the ac distance relay (i.e. at busbar A in Fig. 6) in the event of a dc-side fault, however the approach outlined could also provide a transfer trip to a more local CB or potentially a load-interrupting switch (which may be usable as fault currents are relatively low) to minimize the isolation of healthy ac circuits in an interconnected network. If the fault is successfully cleared by more the local switchgear, the $\mathrm{CB}$ at busbar A could be automatically reclosed.

A quadrilateral impedance characteristic has been used for these studies, as it is easy to implement on standard commercially available relays. It may be preferable to define a more customized shape (i.e. via specific R-X co-ordinates to create a specific boundary) to improve performance. This could readily be achieved via modifications to distance protection relay configuration and setting software.

\section{CONCLUSION}

The role and effectiveness of existing network protection strategies must be validated for situations where dc interconnectors, with converter interfaces, are introduced within existing networks. This paper has presented the results of an investigation into the impacts on power system protection performance from the introduction of embedded MVDC links into distribution networks and has shown how distance protection can be modified to provide backup protection, should a fault on the dc link not be cleared by the main protection for that link.

Through simulations presented in this paper the impedance of dc-side PPG and PP faults, as measured remotely from the ac network, are determined. Using this characteristic, a fastacting backup protection strategy has been established. The developed solution is demonstrated for faults across the length of the dc link with the protection performing as expected.

Studies have shown that existing ac distance protection relays have the flexibility and responsiveness to discriminate and react quickly to faults upon a dc link in a backup mode. 


\section{APPENDIX}

TABLE VI

SUMMARY OF MODELLED EleCTRICAL PARAMETERS

\begin{tabular}{ll}
\hline \hline \multicolumn{1}{c}{ Parameter } & \multicolumn{1}{c}{ Value } \\
\hline Local \& remote grid voltage (line-line) & $33 \mathrm{kV}$ \\
Local \& remote X/R ratio & 7 \\
Local \& remote grid fault level & $500 \mathrm{MVA}$ \\
A-B line length & $5 \mathrm{~km}$ \\
B-C line length & $5 \mathrm{~km}$ \\
MVDC line length & $10 \mathrm{~km}$ \\
Conductor impedance & $(0.17+\mathrm{j} 0.3) \Omega / \mathrm{km}$ \\
MVDC link voltage & $\pm 27 \mathrm{kV}$ \\
MVDC link power rating & $35 \mathrm{MW}$ \\
DC link capacitor value $\left(C_{l}, C_{2}\right)$ & $1 \mathrm{mF}[42]$ \\
Filter impedance $\left(Z_{\text {Filter }}\right)^{\mathrm{a}}$ & $10 \%$ \\
Transformer impedance $\left(Z_{X f m r}\right)^{\text {a }}$ & $20 \%$ \\
Transformer vector group & Yd11 \\
Transformer rated power & $35 \mathrm{MVA}$ \\
Transformer rated voltage & $33: 33 \mathrm{kV}$ \\
\hline \hline
\end{tabular}

${ }^{\mathrm{a}}$ Impedances referred to 35 MVA base

\section{REFERENCES}

[1] L. N. Ochoa, F. Pilo, A. Keane, P. Cuffe and G. Pisano, "Embracing an Adaptable, Flexible Posture: Ensuring That Future European Distribution Networks Are Ready for More Active Roles," IEEE Power and Energy Magazine, vol. 14, no. Sept.-Oct., pp. 16-28, 2016.

[2] M. J. Dolan, M. Barnacle, S. Gill, C. Foote, G. W. Ault and G. Bell, "Modelling and delivery of an active network management scheme for the Northern Isles New Energy Solutions project," in 22nd International Conference and Exhibition on Electricity Distribution (CIRED 2013), Stockholm, Sweden, 2013.

[3] L. Kane, R. West, R. Taljaard, R. Macdonald, G. Ault, E. Davidson and A. Gooding, "Supporting DER customer participation in active distribution networks and local markets," CIRED - Open Access Proceedings Journal, vol. 2017, no. 1, pp. 2019 - 2022, 2017.

[4] N. Kirby, "Current Trends in dc: Voltage-Source Converters," IEEE Power and Energy Magazine, vol. 17, no. 3, pp. 32 - 37, 2019.

[5] F. Mura and R. W. De Doncker, "Design Aspects of a Medium-Voltage Direct Current (MVDC) Grid for a University Campus," in 8th International Conference on Power Electronics - ECCE Asia, Korea, 2011.

[6] J. King, J. Berry and N. Murdoch, "Steady-state modelling for the integration of a bi-directional AC-DC-AC flexible power link," CIRED - Open Access Proceedings Journal, vol. 2017, no. 1, pp. 445-449, 2017.

[7] "Initial designs for ANGLE-DC project: challenges converting existing AC cable and overhead line to DC operation," CIRED - Open Access Proceedings Journal, vol. 2017, no. 1, pp. 2374 - 2378, 2017.

[8] L. Qu, Z. Yu, Q. Song, Z. Yuan, B. Zhao, D. Yao, J. Chen, Y. Liu and R. Zeng, "Planning and analysis of the demonstration project of the MVDC distribution network in Zhuhai," Frontiers in Energy, vol. 13, no. 1, p. 120-130, 2019.

[9] Siemens, "MVDC Plus," 2017. [Online]. Available: siemens.com/mvdc.

[10] GE, "GE Supports Power Grids of the Future with Europe's First MVDC Link," GE Power Conversion, 16 May 2017. [Online]. Available: https://goo.gl/gzJkR9. [Accessed July 2018].

[11] R. M. Cuzner and V. Singh, "Future Shipboard MVdc System Protection Requirements and Solid-State Protective Device Topological Tradeoffs," IEEE Journal of Emerging and Selected Topics in Power Electronics, vol. 5, no. 1, pp. 244-259, 2017.

[12] J. Fabre, P. Ladoux, E. Solano, G. Gateaul and J.-M. Blaquière, "MVDC Three-Wire Supply Systems for Electric Railways: Design and Test of a Full SiC Multilevel Chopper," IEEE Transactions on Industry Applications, vol. 53, no. 6, pp. 5820-5830, 2017.

[13] C. Yuan, M. A. Haj-ahmed and M. S. Illindala, "Protection Strategies for Medium-Voltage Direct-Current Microgrid at a Remote Area Mine Site," IEEE Transactions on Industry Applications, vol. 51, no. 4, pp. 28462853, 2015.
[14] The Alaska Center for Energy and Power, "Small-Scale High Voltage Direct Current," University of Alaska Fairbanks, Fairbanks, 2013.

[15] C. Cleary and S. Hay, "DC Array Refresh Study," TNEI Services Ltd, Manchester, UK, 2018.

[16] W. Chen, A. Q. Huang, C. Li, G. Wang and W. Gu, "Analysis and Comparison of Medium Voltage High Power DC/DC Converters for Offshore Wind Energy Systems," IEEE Transactions on Power Electronics, vol. 28, no. 4, pp. 2014-2023, 2013.

[17] F. P. Page, Analysis in Circuit Breaker Performance Requirements for High-Voltage DC Networks, 2016.

[18] T. Xu, M. W. Donoghue and C. C. Davidson, "IGBT overcurrent turnoff tests for the MMC-based VSC valves," in 15th European Conference on Power Electronics and Applications (EPE), Lille, France, 2013.

[19] M.Wang, M. Abedrabbo, W. Leterme, D. V. Hertem, C. Spallarossa, S. Oukaili, I. Grammatikos and K. Kuroda, "A Review on AC and DC Protection Equipment and Technologies: Towards Multivendor Solution," in CIGRÉ 2017 Colloquium (Study Committees A3, B4 \& D1), Winnipeg, Canada, 2017.

[20] L. He, C.-C. Liu, A. Pitto and D. Cirio, "Distance Protection of AC Grid With HVDC-Connected Offshore Wind Generators," IEEE Transactions on Power Delivery, vol. 29, no. 2, pp. 493-501, 2014.

[21] A. K. Pradhan and G. Joos, "Adaptive Distance Relay Setting for Lines Connecting Wind Farms," IEEE Transactions on Energy Conversion, vol. 22, no. 1, pp. 206 - 213, 2007.

[22] A. Dyśko, J. R. McDonald, G. M. Burt, J. Goody and B. Gwyn, "Integrated Modelling Environment: A Platform for Dynamic Protection Modelling," IEEE, New Orleans, LA, USA, 1999.

[23] P. M. Anderson, Power System Protection, Wiley-IEEE Press, 1999.

[24] J. G. Andrichak and G. Alexander, Distance Relays Fundamentals, GE Power Management, 2002.

[25] Alstom Grid, Network Protection \& Automation Guide, 2011.

[26] Scottish \& Southern Electricity Networks (SSEN), "Long Term Development Statement," Scottish and Southern Energy Power Distribution Limited, Perth, 2016.

[27] G. Adam, K. Ahmed, S. Finney and B. Williams, "AC fault ride-through capability of a VSC-HVDC transmission systems," in IEEE Energy Conversion Congress and Exposition, Atlanta, GA, USA, 2010.

[28] P. D. Judge, M. M. C. Merlin, T. C. Green, D. R. Trainer and K. Vershinin, "Thyristor-Bypassed Submodule Power-Groups for Achieving High-Efficiency, DC Fault Tolerant Multilevel VSCs," IEEE Transactions on Power Delivery, vol. 33, no. 1, pp. 349 - 359, 2017.

[29] J. Yang, J. E. Fletcher and J. O'Reilly, "Short-Circuit and Ground Fault Analyses and Location in VSC-Based DC Network Cables," IEEE Transactions on Industrial Electronics, vol. 59, no. 10, pp. 3827 - 3837, 2012.

[30] G. Tang, Z. Xu and Y. Zhou, "Impacts of Three MMC-HVDC Configurations on AC System Stability Under DC Line Faults," IEEE Transactions on Power Systems, vol. 29, no. 6, pp. 3030 - 3040, 2014.

[31] I. A. Gowaid, "A Low-Loss Hybrid Bypass for DC Fault Protection of Modular Multilevel Converters," IEEE Transactions on Power Delivery, vol. 32, no. 2, pp. 599-608, 2017.

[32] W. Leterme and D. V. Hertem., "Classification of fault clearing strategies for HVDC grids," in CIGRE Symposium, Lund, 2015.

[33] L. Hunter, C. Booth, A. J. Ferre and S. Finney, "MVDC for enhanced utility scale distribution power delivery and control," in 52nd International Universities Power Engineering Conference (UPEC), Heraklion, 2017.

[34] R. Teodorescu, M. Liserre and P. Rodriguez, Grid Converters for Photovoltaic and Wind Power Systems, John Wiley and Sons Ltd, 2011.

[35] A. Egea-Alvarez, A. Junyent-Ferré and O. Gomis-Bellmunt, Modeling and Control of Sustainable Power Systems - Active and Reactive Power Control of Grid Connected Distributed Generation Systems, Springer Science \& Business Media, 2012

[36] S. D'Arco, J. A. Suul and J. Beerten, "Configuration and model order selection of frequency-dependent $\pi$-models for representing dc-cables in small-signal eigenvalue analysis of HVDC transmission systems," IEEE 
Journal of Emerging and Selected Topics in Power Electronics, pp. 1-1, 2020.

[37] GEC Measurements, "MicroMho - Static Distance Protection Relay," The General Electric Company p.l.c. England, Stafford, 1984.

[38] Alstom Grid, "Technical Manual - MiCOM P543-P546," Alstom Grid, Stafford, UK, 2011.

[39] L. Hunter, C. Booth, A. Dysko, S. Finney and A. Junyent-Ferré, "The impact of MVDC upon conventional distance protection schemes in hybrid ac-dc distribution networks," in IET ACDC 2019, The 15th IET International Conference on AC and DC Power Transmission (ACDC 2019), 2019.

[40] B. Ravindranath and M. Chander, Power System Protection and Switchgear, New Delhi: New Age International Limited, 2005.

[41] M. Wang, W. Leterme, G. Chaffey, J. Beerten and D. V. Hertem, "Pole Rebalancing Methods for Pole-to-Ground Faults in Symmetrical Monopolar HVDC Grids," IEEE Transactions on Power Delivery, vol. 34, no. 1, pp. 188 - 197, 2019.

[42] T. Joseph, J. Liang, G. Li, A. Moon, K. Smith and J. Yu, "Dynamic control of MVDC link embedded in distribution network: - Case study on ANGLE-DC," in IEEE Conference on Energy Internet and Energy System Integration (EI2), Beijing, China, 2017.

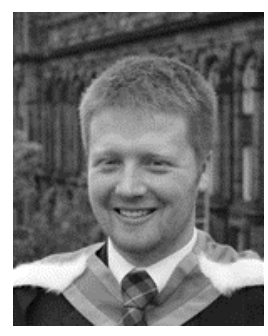

Lewis C. Hunter (S'16) received the M.Eng. degree in electrical and electronic engineering from the University of Strathclyde, Glasgow, Scotland in 2015. $\mathrm{He}$ is currently finalizing a Ph.D. degree through the EPSRC Centre for Doctoral Training in Future Power Networks and Smart Grids at the same institution. His primary research interests include future power system protection and protection of hybrid ac/dc networks.

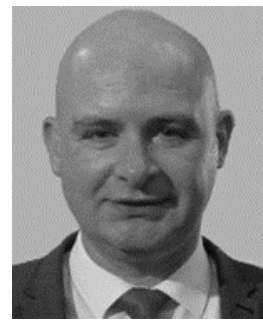

Campbell D. Booth received the B.Eng. and Ph.D. degrees in electrical and electronic engineering from the University of Strathclyde, Glasgow, Scotland, in 1991 and 1996, respectively. He is currently a Professor and the Head of Department for Electronic and Electrical Engineering, University of Strathclyde, Glasgow, U.K. His research interests include power system protection; plant condition monitoring and intelligent asset management; applications of intelligent system techniques to power system monitoring, protection, and control; knowledge management; and decision.

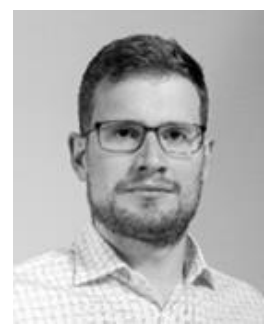

Agusti Egea-Alvarez (S'12-M'14) is Strathclyde Chancellor's fellow (Lecturer) at the electronic \& electrical engineering department and member of the PEDEC (Power Electronics, Drives and Energy Conversion) group since 2018. He obtained his BSc, MSc and $\mathrm{PhD}$ from the Technical University of Catalonia in
Barcelona in 2008, 2010 and 2014 respectively. In 2015 he was a Marie Curie fellow in the China Electric Power Research Institute (CEPRI). In 2016 he joined Siemens Gamesa as converter control engineer working on grid forming controllers and alternative HVDC schemes for offshore wind farms. He is a member of IEEE, IET and has been involved in several CIGRE working groups.

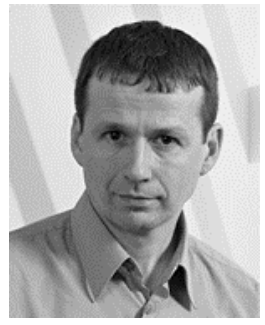

Adam Dyśko (M'06) received the Ph.D. degree in Electrical and Electronic Engineering from the University of Strathclyde, Glasgow, Scotland, in 1998. He is currently a Senior Lecturer with the Department of Electronic and Electrical Engineering. He teaches a variety of Electrical Engineering subjects and has been leading several research projects with both academic and industrial partners. His research interests include power system protection, control and stability, and power quality.

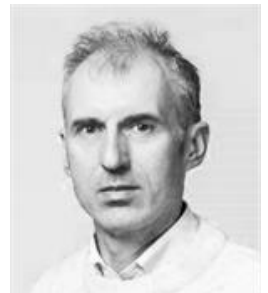

Stephen J. Finney received the M.Eng. degree in electrical and electronic engineering from the Loughborough University of Technology, Loughborough, U.K., in 1988, and the Ph.D. degree from Heriot-Watt University, Edinburgh, Scotland, in 1994. He joined the University of Edinburgh, Edinburgh, as a Professor of Electrical Engineering in 2017. His current research interests include power electronics for high-power applications and the management of distributed energy resources.

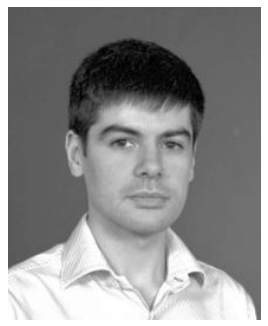

Adria Junyent-Ferre (S'09-M'11SM'19) obtained his Industrial Engineering degree from the School of Industrial Engineers of Barcelona (ETSEIB), Polytechnic University of Catalonia (UPC) in 2007, and the Ph.D. in Electrical Eng. from the UPC in 2011. He was a Researcher at CITCEA-UPC from 2006 to 2012 and a Lecturer at the Barcelona College of Industrial Engineering (EUETIB) in 2012. He joined the Dept. of Electrical and Electronic Eng. at Imperial College London in 2013 and became a Lecturer in 2014. His research focuses on control of power electronic converters and their design, with specific focus on wind power, VSC-HVDC and microgrids. 